\title{
CONSIDERAÇÕES SOBRE A TRANSMISSÃO DE TEXTOS LATINOS EM LÍNGUA VULGAR PORTUGUESA NOS SÉCULOS XV E XVI
}

\author{
Flávio Antonio Fernandes Reis ${ }^{1}$
}

RESUMO: Apesar do desprezo dos estudiosos pelas vulgarizações dos séculos XV e XVI, elas são um meio importante de transmissão dos textos antigos gregos e latinos. O confronto das línguas vulgares com as antigas leva a mudanças lexicais e sintáticas que modificam a língua de chegada. Em Portugal, desde pelos menos o século XV há considerável interesse em vulgarizar textos antigos, sobretudo os tratados morais de Cícero. Em diversos documentos encontramos as dificuldades dos letrados em face dos textos antigos. Apesar disso, o proveito das matérias das auctoritates greco-latinas os impele a publicarem suas vulgarizações.

PALAVRAS-CHAVE: Recepção Latina; vulgarização; Corte de Avis; Cícero.

RÉSUMÉ: Bien que la plupart des spécialistes méprisent les vulgarisations du XVème et XVIème siècles, elles sont d'importants moyens pour la transmission des textes grecques et latines antiques. Le contact des langues vulgaires avec les langues antiques produit des changements dans le vocabulaire et les structures de la langue moderne. Au Portugal, depuis le XVème siècle il y a l'intérêt pour la composition des textes antiques en portuguais, surtout les œuvres morales de Cicéron. Plusieurs documents montrent les difficultés de l'auteur moderne face aux textes antiques, mais les sujets profitables de ces écrits antiques, c'est-à-dire l'importance des auctoritates, amènent les modernes à faire des vulgarisations.

MOTS-CLÉS: Reception latine ; vulgarisation ; Cour d'Avis ; Cicéron.

\footnotetext{
${ }^{1}$ Mestre em Literatura Portuguesa no DLCV - USP. Bolsista da FAPESP.
} 
Neste artigo apresentamos notas sobre a prática da vulgarização, sobretudo, de tratados morais de Cícero no Portugal dos séculos XV e XVI. Evitamos o uso generalizado do termo "tradução" pelas implicações que esta palavra possui nas reflexões atuais de linguagem. Quando optamos pelo uso mais recorrente do termo "vulgarização", referimo-nos à prática difundida, pelo menos desde o século XV nas letras portuguesas, de acomodação da língua vulgar ao latim, dito no tempo como “tornar em linguagem”, com preocupações elocutivas e, mais ainda, com fins éticos de salvaguardar na língua vulgar os ensinamentos morais do texto latino. Nesse sentido, “tornar em linguagem" ou "vulgarizar" difere-se da recente noção de traduzir, já que pressupõe a assimilação da língua latina pelo vernáculo, principalmente no século XVI, com a tópica nomeada posteriormente de "questão da língua".

$\mathrm{O}$ interesse pelos mesmos textos em tempos diversos aponta para a variedade de apelos destas fontes em diferentes apropriações. As novas reescrituras trazem soluções formais e interpretativas que nos permitem compreender os valores atribuídos à fonte revisitada, reconstituindo de modo verossímil a recepção do texto nas suas diferentes refacções. Assim, a caracterização das diversas apropriações e o confronto com as questões pertinentes de cada tempo possibilita uma compreensão historicizada das obras e autores de grande fortuna, que por razões diversas, mereceram edições e atualizações em diferentes momentos. Com isso, as vulgarizações, as dedicatórias, prólogos e cartas que lhe fazem nota figuram como vestígios de um tempo desaparecido, agora precário, porém, ainda cognoscível na dramatização dos resquícios que nos chegaram.

Como analisamos em cartas e prólogos dos séculos XV e XVI, os textos escolhidos para serem "tornados em linguagem" são primordialmente obras de filosofia moral que se colocam como modelos de conduta moral para os leitores e, de modo secundário, como modelos de prosa filosófica em língua vernácula. Por estes e outros motivos, Gilbert Highet considera as traduções quinhentistas como um dos principais meios de transmissão dos textos greco-latinos nas letras do Ocidente. Segundo Highet, a tradução é uma arte negligenciada pelos estudiosos e a sua importância artística e lingüística, sobretudo no século XVI, é quase tão grande quanto o campo das idéias (HIGHET, 1970, p. 106). As vulgarizações geralmente impõem desafios à língua de chegada, resultando no acréscimo de palavras e estruturas sintáticas do latim, em grande medida e, por vezes, do grego. Por conta disso, no século XVI, a abundancia dos 
latinismos, tanto sintáticos quanto lexicais, evidenciam uma "latinização" da língua vulgar, configurando a tópica do tempo segundo a qual tanto melhor seria a língua vulgar quanto mais se assemelhasse ao latim. Nesse sentido, as apropriações sintáticas e lexicais resultam em modificações estilísticas consideráveis para a elocutio na escrita vernácula desde então.

Os letrados quinhentistas cultivaram em larga medida a composição de vulgarizações dos autores latinos e gregos em suas línguas vernáculas. Highet afirma que foi o "Renascimento a grande idade da tradução" porque tão rapidamente quanto eram descobertos os autores, do mesmo modo eram vulgarizados em várias línguas européias. Acrescente-se a isto o fato de que nos séculos XV e XVI há um grande entusiasmo em encontrar e recuperar os textos dos autores antigos, tais como as célebres buscas de Petrarca por manuscritos em mosteiros e bibliotecas antigos. Mais ainda, há um crescente interesse em divulgar os textos de excelência das auctoritates grecolatinas por meio da imprensão, em atividade desde meados do século XV na Europa. Com o costume mais generalizado de redigir em vernáculo, as línguas que mais se destacaram na composição de textos antigos em vulgar foram o francês, o inglês, o alemão, o italiano e o castelhano. De fato, desde o século XIV, pelos menos nas cidades italianas, o uso do toscano é recorrente na redação de obras relevantes, tais como os textos de Dante, Petrarca e Boccaccio, para citar alguns mais conhecidos. Muitos letrados italianos realizaram vulgarizações e redigiaram suas obras em vernáculo, imitando nelas os modelos de escrita antigos. Com isso, restabeleceram-se muitos gêneros antigos que praticamente estavam desaparecidos e foram conhecidos outros modelos para a escrita em prosa para além daqueles de costume. Mesmo assim, na prosa filosófica, Cícero e Sêneca seguiam como modelos por excelência e os tratados ciceronianos como o De amicitia (Da amizade) e o De Senectude (Da Velhice) nunca deixaram de ser lidos e imitados, além das diversas vulgarizações em línguas vernáculas: Laurent Premierfait, morto em 1418, fez a primeira vulgarização dos tratados morais ciceronianos para o francês ainda no início do século XV. Cícero foi vulgarizado em inglês antes de 1460 por John Tiptoft, conde de Worcester, livro impresso por Caxton em 1481 juntamente com o texto francês do De Senectude de Premierfait. Em 1434, os tratados ciceronianos foram reunidos numa compilaçao intitulada Cícero Germânico, feita por John, Freiherr zu Schwarzenberg. Jean Colin 
vulgarizou todos estes tratados de Cícero para o francês entre 1537 e 1539 e John Harinton o fez com o De Amicitia da versão francesa em 1550. Whittington vulgarizou o De Senectude em 1535 e Thomas Newton o fez novamente em 1577. Os três livros do De Officiis ciceroniano foram vulgarizados para o alemão ainda no século XV em 1488 e de novo em 1531 por Schwarzenberg. As Questões Tusculanas foram passadas para o francês por Étienne Dolet por volta de 1542 e para o inglês em 1561 por John Dolman. Schaidenreisser vulgarizou as Paradoxas para o alemão em 1538, Whittington para o inglês em 1540 e Thomas Newton de novo em 1569, que publicou juntamente com o fragmentário Sonho de Cipião, textos estes que foram vulgarizados no século XVI para o Espanhol e o português. (HIGHET, 1970, PP. 119-120)

O marquês de Santillana, numa carta dirigida ao filho Pero Ganzález de Mendoça, demonstra seu entusiasmado gosto por "tornar em linguagem" os textos latinos antigos. Santillana menciona ter recebido de um amigo italiano um conjunto considerável de textos, entre os quais se encontravam obras de "Leonardo de Areçio" (Leonardo de Arezzo), Pero Caudiño e “daquele príncipe de los poetas Homero, e de la História Troyana, que él compuso, a la qual Iliade intitulo, traduçidos del griego a llengua latina". O texto de Homero em latim é a principal matéria da missiva, e assim, lembrando o exemplo de outros letrados e os proveitos das vulgarizações de textos antigos, Santillana pede a Pero González que se disponha a passar a Historia de Tróia para a lingua castelhana:

E como quier que por Guydo de Columma e informados de las relaciones de Ditis, griego, e Dares, phrigio, e de otros muchos auctores, assaz plenaria e extensamente ayamos notiçia d'aquéllas, agradable cosa será a mi ver obra de un tan alto varón e quassi soberano príncipe de los poetas, mayormente de um litígio militar o guerra, el mayor e más antiguo que se cree aver seydo em el mundo. E asy, ya sea que non vos fallescan trabajos de vuestros estúdios, por consolaçión e utilidat mia e de otros, vos ruego mucho vos dispongades; e pues que ya el mayor puerto, e creo de mayores fragosidades, lo passaron aquellos dos prestantes varones, lo passedes vos el segundo, que es de la lengua latina al nuetro catellano idioma.. ${ }^{2}$

\footnotetext{
${ }^{2}$ Don Iñigo López de Mendoça, Marqués de Santillna, Conde del Real, a Don Pero Ganzález de Mendoça. Protonotário, su fijo, Escrive: Salut. In: El Marquês de Santillana: Obras. Madrid: EspasaCalpe, 1956, p. 43. Podemos observar como os autores antigos são considerados como autoridade letradas e éticas, sendo por isso convenientes à vulgarização. O marques de Santillana é considerado como uma dos letrados mais ativos no século XV castelhano no estímulo às edições dos antigos em língua vulgar.
} 
Santillana menciona a Historia destructionis Troiae, uma versão latina trecentista do poeta siciliano Guido Columna, baseada em textos de Dares Frígio e Dictys, o grego. A obra de Guido foi amplamente divulgada e traduzida para o italiano, francês, inglês, alemão, dinamarquês, islandês, entre outras.

A metáfora do "porto" utilizada pelo marquês merece nota. A versão de Ditis e Dares, as duas fontes helênicas mencionadas por Guido e lembradas por Santillana, seriam o primeiro porto, de "mayores fragosidades", enquanto a vulgarização de Pero González seria o segundo, no qual se daria o principal fim da versão castelhana: "consolaçión e utilidat mia e de otros". Nesse sentido, a imagem do "porto" como feliz desfecho e consolação aproxima o exercício da vulgarização à atividade náutica, atribuindo-lhe os seus significados mais imediatos tais como a novidade, a descoberta, a expansão dos saberes e as trocas. Mais ainda, o argumento da "utilidade e do proveito de outros" aponta para os usos éticos decorrentes da divulgação do texto em língua vulgar e caracteriza-se como uma das principais tópicas associadas à vulgarização dos textos antigos nos séculos XV e XVI.

Por meio da tópica da humilitas oratória, conveniente à uma carta de pedido, e também como argumento em favor das vulgarizações, Santillana destaca a insuficiência de seu latim para a leitura de textos não eclesiásticos. Para tanto, diz-se incapaz de seguir o exemplo de Catão, que segundo o Tratado da Velhice de Cícero "em etat de octenta años aprehendiesse las letras griegas", pois "solo e singular fué Catón del linage humano en esto e en otras muchas cosas". (MARQUÉS DE SANTILLANA, 1956, P. 44) Santillana, mais uma vez, com o intuito de persuadir seu filho a compor a vulgarização da Historia Troyana, menciona os textos que por seu intermédio foram compostos em língua vulgar castelhana:

A ruego e instançia mia, primero que de outro alguno, se han vulgariçado em este reyno algunos poemas, asy como la Eneyda de Virgillio, el libro mayor de las transformaçiones de Ovidio, las Tragedias de Lucio Anio Séneca, e muchas otras cosas em que yo me he deleytado fasta este tiempo e me deleyto, e son asy como un singular reposo a las vexaciones e trabajos que el mundo continuamente trahe, mayormente em estos nuestros reynos. Asy que, aceptado por vos el tal cargo, prinçipalmente por la excelência de la matéria e clara forma forma del poeta, e después por el traduçidor, non dubdedes esta obra que todas las otras será a mi muy más grata. (MARQUÉS DE SANTILLANA, 1956, p. 44) 
A composição de textos antigos em língua romance é motivada pelos proveitos éticos, presentes na excelência da matéria, e elocutivos, pela "clara forma" do poeta e também do "traduçidor" Guydo Columma. Para a história da circulação dos textos antigos e seus diversos gêneros na Península, é bastante significativo o conjunto de textos mencionados por Santillana que contempla a epopéia de Virgílio, as narrativas cosmogônicas das Metamorfoses e o teatro trágico de Sêneca, além das "muchas otras cosas" que o marquês não menciona. Esta passagem evidencia o acesso de Santillana às obras latinas antigas e muito nos interessa, dada as relações de proximidade entre o marquês e membros da corte portuguesa. ${ }^{3}$

Apesar do entusiasmo de Santillana pelos textos antigos em língua vulgar e das declarações do tempo que enaltecem os proveitos oratórios e morais destas obras, os manuais de história literária lhes dão pouca atenção e valor. No caso das letras portuguesas, muitas vezes as considerações sobre as vulgarizações antigas aparecem na crítica como breves menções ou listagem de textos sem preocupações analíticas mais profundas. Mais ainda, muitos estudiosos, insensíveis à uma leitura de época das vulgarizações cometem o anacronismo crítico de exigir-lhes as qualidades ou recursos das traduções contemporâneas. Este tipo de abordagem leva à consideração dos textos como deficientes, incompletos, mal feitos e merecedores de descaso. Trata-se de um outro tempo, uma outra relação com as auctoritates antigas e seus textos, uma temporalidade que desconhece a noção de tradição como acúmulo e se baseia na jurisprudência de costumes escritos para o funcionamento das letras. Todas estas variáveis devem ser ponderadas no julgamento mais acertado das vulgarizações dos séculos XV e XVI dos autores greco-latinos, pois, o fim não é responder se a tradução é boa ou não, juízos vagos e insuficientes como crítica para texto antigo, mas compreender o modo de funcionamento destas composições segundo seus determinantes.

Luis de Sousa Rebelo em A tradição clássica na literatura portuguesa, mesmo que incentive os pesquisadores à análise das antigas vulgarizações greco-latinas feitas

\footnotetext{
${ }^{3}$ Não podemos nos esquecer da carta que Santillana enviou a D. Pedro, o condestável de Portugal, filho do Infante D. Pedro de Coimbra, enviando-lhe algumas obras encomendadas pelo próprio condestável. Nesta missiva, Santillana faz uma graciosa defesa da poesia e da eloqüencia "dulce e fermosa fabla, sea metro, sea prosa" e demonstra seu profundo conhecimento de obras e autores antigos, tanto pagãos como cristãos, e de letrados como Dante, "Petrarcha" e "Johan Bocaçio", para citar alguns. Cf. Comiença el prohemio e carta quel marqués de Santillana envió al Condestable de Portugal com lãs obras suyas. In: $E l$ Marquês de Santillana: Obras, p. p. 29-41.
} 
em Portugal, esclarece que em seu livro, dado a natureza de sua proposta crítica, buscou estabelecer uma linha de desenvolvimento das traduções e revelar os seus fatores histórico-culturais sem fazer um inventário sistemático das obras clássicas vertidas para o vernáculo. Para tanto, Rebelo mencionou desde as primeiras traduções realizadas nos mosteiros (a Regra de São Bento, a Vita Christi do fr. Bernardo de Alcobaça), passando pelos quinhentistas (Duarte de Resende, Damião de Góis, Diogo de Teive, André Falcão de Resende entre outros) até as traduções setecentistas feitas por Francisco José Freire, o Cândido Lusitano.

Álvaro da Costa Pimpão, na sua História da Literatura Portuguesa, menciona várias vulgarizações de autores gregos e latinos no intuito de confirmar o vigor do que ele chama de "cultura clássica" em Portugal. Noutra conhecida História da Literatura Portuguesa de José Saraiva e Óscar Lopes, encontramos menções às traduções do século XV português no intuito de indicar os aspectos da prosa doutrinária na corte quatrocentista. Na relação de obras apresentada por Saraiva está o nome de Cícero, Santo Agostinho, os Evangelhos canônicos e os Actos dos Apóstolos, e cita-se especificamente a obra de Regídio Romano, o Regimento dosPríncipes, sem lembrar da tradução desta obra feita pelo Dr. Vasco Fernandes de Lucena e dedicada a D. Afonso V. Menciona-se ainda a tradução, feita de fonte francesa, do Espelho de Cristina ou Livro das Três Virtudes de Christine de Pisan, também a Arvore das Batalhas e a Confissão do Amante de John Gower. Já na apreciação do Livro da Virtuosa Benfeitoria, atribuído a D. Pedro de Coimbra, Saraiva tece considerações gerais sobre as transformações formais da língua vernácula no contato com as línguas grega e latina (cf. SARAIVA, 1996, p. 111 e segs.).

Maria Leonor Carvalhão Buescu, no prefácio de sua edição das vulgarizações quinhentistas de Duarte de Resende, buscou caracterizar o interesse pelas obras de Cícero no início do século XVI português. Apesar de seu prólogo trazer muitas notícias acerca das apropriações ciceronianas na história das letras portuguesas desde a chamada Idade Média, a autora não teve a preocupação de analisar detidamente os textos de Resende editados por ela, nem ao menos dar-lhes uma edição com cuidados críticos mais apurados. Ela nem ao menos informa que leu a segunda edição de 1790 dos textos de Duarte de Resende. No entanto, mesmo com todas estas faltas críticas, a edição de 
Buescu contribui para a divulgação das vulgarizações quinhentistas de Cícero entre o "grande" público.

Por outro lado, estudos como os de Joseph Piel, Jorge Alves Osório e J. Mendes de Castro sobre as vulgarizações de Cícero dos séculos XV e XVI buscam precisar seus aspectos históricos, lingüísticos e culturais. Piel, no prólogo da sua edição do Livro dos Ofícios, vulgarizado por D. Pedro de Coimbra no século XV, confrontou esta obra com outras vulgarizações do mesmo tempo e investigou o interesse do Infante em disponibilizar o tratado ciceroniano na língua vulgar portuguesa. Mais ainda, Piel teve o cuidado de fazer o cotejo entre o texto latino de base e a edição quatrocentista, verificando com precisão o léxico utilizado por D. Pedro para os termos latinos pouco familiares ao leitor quatrocentista. O pesquisador verificou ainda as estratégias de adaptação do texto latino para o vernáculo: a característica das frases, o léxico, as parte do texto vulgar de difíceis compreensão para o leitor de hoje. Jorge Alves Osório estudou especificamente duas vulgarizações quinhentistas: o Tratado da Velhice, vulgarizado por Damião de Góis em 1538, e o Tratado da Amizade, publicado por Duarte de Resende em 1531 nas prensas coimbrãs do Mosteiro de Santa Cruz sob os cuidados de Germão de Galharde. Osório, em suas considerações analíticas, valeu-se de informações trazidas nos prólogos das obras e nas discussões lingüísticas e culturais do tempo dos textos estudados, sobretudo, as relações do chamado humanismo português com as idéias erasmistas em voga.

Estes estudos evidenciam como os textos antigos vulgarizados eram, em certa medida, modelos de eloqüência a serem imitados na língua vernácula. Mais ainda, o interesse primordial está na possibilidade da língua vulgar transmitir de modo eficiente a sabedoria antiga para o proveito dos leitores quinhentistas, uma das repercussões da chamada “questão da língua", tópica quinhentista definida em obras como Diálogo em Louvor da Nossa Linguagem, de João de Barros; Dialogo de la Lengua de Juan Luis Valdés e o Prose della Volgar Lingua de Pietro Bembo.

As vulgarizações de textos ciceronianos feitas por Duarte de Resende e Damião de Góis no século XVI integram uma prática de pelo menos um século desde as primeiras composições de textos latinos em língua vulgar feitas na Corte de Avis, tais como o Livro dos Oficios, o Livro da Virtuosa Benfeitoria de D. Pedro de Coimbra, o Tratado da Velhice de Vasco Fernandes de Lucena e outros. Segundo Joseph Piel, o 
Livro dos Ofícios de D. Pedro pode ser considerado uma das primeiras obras ciceronianas a receber edição completa em língua portuguesa. ${ }^{4}$ Nele e em outros, o confronto da língua vernácula com obras latinas impõe ao vernáculo grandes desafios formais e interpretativos, tal como podemos verificar na leitura dos prólogos, dedicatórias e cartas do período. O infante D. Pedro de Coimbra, por exemplo, na dedicatória do seu livro a D. Duarte, menciona a dificuldade impostas por "lugares scuros" encontrados na lição do texto latino, ou ainda, refere-se também à existência de “partes escritas para quem já as sabia” (PIEL, 1948, P. 4). Já Vasco Fernandes de Lucena, num trecho de sua carta ao Infante, fala de semelhantes dificuldades ao reclamar dos "falecimentos" do texto, que os tornavam resistentes às "sentenças desvayradas dos invejosos"(in PIEL, 1948, P. XLIII).

Por outro lado, apesar dos obstáculos mencionados, as vulgarizações foram realizadas e algumas constam na relação das obras da "Livraria de D. Duarte". Mais ainda, elas aparecem referidas em textos que chegaram ao nosso tempo tais como cartas, prólogos e dedicatórias. Nas cartas trocadas entre D. Pedro e o letrado Vasco Fernandes de Lucena, os argumentos favoráveis à prática da trasladação denotam o prestígio destes textos na corte, principalmente pelo interesse de que estes textos fossem proveitosos ao "não latinados", aos falantes da "linguagem mais comum no reino". Muitos argumentos como o "proveito para muitos do reino" e "o valor das matérias trazidas pelos antigos", apesar das falhas na transposição do estilo, aparecem de modo semelhante na carta do marquês de Santillana mencionada anteriormente. Desse modo, esses argumentos parecem configurar um lugar comum do tempo para a defesa das vulgarizações, presente também em prefácios franceses, como é o caso da "Dedicatória" da Vida de Alexandre de Quinto Curcius, traduzida por Vasque de Lucéne na corte de Borgonha (BOSSUAT, 1946, P. 210). O argumento do proveito das letras para muitos evidencia um reconhecimento da utilidade ética da sabedoria antiga aplicada às razões do universo monárquico, servindo como conduta moral para os cortesãos, com o fim de alcançar o "leal conselheiro", título de uma das principais obras de filosofia moral da corte de Avis, constituída pela compilação de diversos autores gentios e cristãos em língua vernácula.

\footnotetext{
${ }^{4}$ Cf. Piel, edição do Livro dos Ofícios do infante D. Pedro de Coimbra, op. cit., p. XXII: "A primeira tradução integral em português de um escritor da Antigüidade, podendo ser interpretado como digno prelúdio àquela vasta actividade literária que, tendo por objetivo a assimilação da sabedoria e formas da era pagã, havia de conduzir ao humanismo propriamente dito."
} 
As vulgarizações quinhentistas demonstram a difusão dos diversos recursos estilísticos, lingüísticos e históricos provenientes da atuação de letrados daquele momento, de modo mais extensivo a partir da segunda metade do século XV, na Itália. De fato, as perspectivas para com as obras antigas se alteram mediante a colaboração de letrados quatrocentistas como Lorenzo Valla e Nebrija; e quinhentistas como Erasmo, Vives, Valdés e Bembo, para citar alguns. Porém, mesmo com o entusiasmo na emulação da elocução antiga na língua vulgar, os apelos morais continuam na tônica das leituras dos textos latinos, sobretudo Cícero. Neste sentido, encontramos na carta dedicatória de Duarte de Resende a Garcia de Resende outra vez a tópica que defende o proveito que o Tratado da Amizade ciceroniano traz à nação portuguesa, pois nela "em muytos esta amizade andar errada e simulada". Jorge Alves Osório sugere que o fato de Resende direcionar seus textos a um fidalgo da condição de Garcia de Resende permite interpretá-los como proposta moral para a realeza:

Não deveria esse grupo (a corte) esclarecer e iluminar os fundamentos de sua própria conduta social e moral, solidificando-os com os modelos e exemplos bem estruturados de uma Antigüidade que legara concepções fundamentais sobre a noção de Estado e das razões a cada grupo social dentro do seu interior? (OSÓRIO, 1984, p. 214)

Por outro lado, a carta dedicatória indica também uma preocupação de Resende em fornecer aos leitores "prudente conhecimento sobre virtuosa tensão", razão pela qual optou por vulgarizar os textos que contemplassem não somente temas da prática política, como poderia ser o caso do De Amicitia, mas também outros que levariam à ponderação das máximas estóicas do "bem agir", como é o caso das Paradoxas dos Estóicos, e por que não espiritual, que é o caso do Somnium Scipionis que expõe os merecimentos post-mortem reservados aos homens justos que melhor serviram à pátria. A carta-dedicatória de Duarte de Resende serve para ilustrar os modos de uso dos textos morais latinos, em particular os de Cícero, na primeira metade do século XVI em Portugal:

eu por me parecer proueytoso a nossa nação purtuguesa: onde vejo em muytos esta amizade errada e simuluda. Quis empreguar minha ociosidade em tirar de latim em nosso lingoajẽ este pequeno tratado della:composto per aquelle fonte de eloquencia. Marco tulio. e sua grade autoridade me deu ousadia para cometer tã periguosa empresa o 
que sinto e vejo ser mal cõsyrado. assy por me falecer sciẽcia pera entender suas prudentes sentẽças copioso e elegãte latim. como copia de palavras purtuguesas craras e polidas para decrarar as que cuydo que entendo: que bẽ creo que nhũa das lingoas de Espanha [e se diser de toda a Europa nã me arepẽderey] tẽ auentagẽ da purtuguesa pera em ella se tratar de graues e excelentes materias. como sam as deste autor. e nã soomente tomey este atreuimẽto neste tratado de Amicicia mas ainda ousey tirar nesta lingoagẽ os três libros de officis e o de de senectute que se intitula Catão mayor cõ Paradoxas e o tratado do sexto libro da republica que se diz o sonho de Scipião. (RESENDE, Coimbra, 1531)

Os usos éticos e elocutivos do texto de Cícero em "linguagem portuguesa" estão aqui explicitados. A autoridade para a ousadia da vulgarização provêm do próprio Cícero, por suas célebres versões latinas de obras filosóficas gregas, sobretudo, as de Platão. Esta mesma tópica é utilizada por Damião de Góis na dedicatória de sua vulgarizacao do Tratado da Velhice ciceroniano, de 1538. Na passagem da carta de Resende também evidencia-se a tópica da valorização da língua vulgar: terá mais vantagem a língua que pode tratar de "graves e excellentes materias" e, assim, a portuguesa está adiante das outras européias. Duarte de Resende refere-se aos livros vulgarizados por ele e, por causa da humilitas retórica, faz objeções às suas limitacoes como letrado, mas não às qualidades da língua vulgar face ao latim. Nesse sentido, Resende reafirma a tópica da língua vulgar, o valor da obra moral de Cícero como modelo oratório e ético e disponibiliza aos seus contemporaneos as principais obras ciceronianas do "bem-agir".

\section{Referências bibliográficas}

BARROS, João de. Diálogo em louvor da nossa linguagem, edição de Luciana Stegagno Picchio, Modena: Società Tipográfica Modenense, 1959.

BOSSUAT, Robert. Vasque de Lucene, traducteur de Quinte-Curce (1468), Bibliothèque d'Humanisme et Renaissance, Tomo VIII, Paris, 1946, pp. 197-245.

HIGHET; Gilbert. Classical Tradition: Greek and Roman Influences on Western Literature, Oxford: Oxford University Press, 1970. 
MENDES DE CASTRO. Damião de Góis: tradutor de Cícero. Euphrosyne. Revista de filologia clássica. vol. XXXI, Lisboa, 2003, pp. 385-394.

SANTILLANA, Marquês de. Obras, edición al cuidado de Augusto Cortina, Madrid: Espasa-Calpe, 1956.

OSÓRIO, Jorge Alves. Duarte de Resende: tradutor do De Amicitia (1531). Humanitas. Coimbra: Instituto de Estudos Clássicos, vol. XLVII, II tomo, 1995, p. 721-738.

PIEL, Joseph. Introdução. In: Livro dos Ofícios, Coimbra: Por Ordem da Universidade, 1948

REBELO, Luis de Sousa. A tradição Clássica na Literatura Portuguesa, Lisboa: Editorial Horizonte, 1982.

RESENDE, Duarte de. Marco tulio cicerom de amicicia pradoxasesonho de Scipião.tirado em lingoagẽ portuguesa p. Duarte de Resende... Coimbra, Germão de Galharde, 1531.

Tratados da amizade, paradoxos e sonho de Scipão. Compostos Por M. T. Cicero Traduzidos de Latim em Linguagem Portugueza Por Duarte de Resende no Anno de 1531. Lisboa: Regia Officina Typographica, 1790. Tratados da amizade, Sonho de Cipião e Paradoxas. "Coleção Clássica". Rio de Janeiro: Organização Simões, 1952.

Tratados da amizade, paradoxos e sonho de Cipião. Edição de Maria Leonor Carvalhão Buescu. Lisboa: Imprensa Nacional-Casa da Moeda, 1982.

SARAIVA, José; Lopes, Óscar. História da Literatura Portuguesa, Porto: Porto Editora, 1996. 